Research Article

Copyright (C) All rights are reserved by Michael D Brazley

\title{
Virtual Reality and Distance Education
}

\author{
Michael D Brazley* \\ Southern Illinois University, USA
}

*Corresponding author: Michael D Brazley, Southern Illinois University, USA.

Received Date: February 12, 2019

Published Date: March 06, 2019

\begin{abstract}
What is the next generation of learning technology: the cellphone, your watch, virtual reality, or all of the above? The research question being asked is: How can Virtual Reality (VR) assist students in learning? This research proves that virtual reality technology does enhance 3D spatial visualization skills of students. Due to the nature of their learning styles, many students need to interact with 3D scenes to enhance their spatial visualization skills, to see and understand the 3D model. This research proves that virtual reality technology will assist in giving both online and face-to-face architectural students a better education and help them to improve their spatial visualization skills.
\end{abstract}

Keywords: Virtual Reality; Spatial visualization

\section{Introduction}

Each year the number of students taking at least one online course increases. This study investigates using virtual reality to increase 3D spatial visualization skills for both online and face-toface teaching of architectural students.

Everyone has their own learning style(s); virtual reality and M-Learning (mobile learning) for architectural students include visual and real-world contexts, followed by verbal information for best results. Interaction between teacher and student, real world problems, and making their own decisions about learning, gives architectural students the most satisfaction with M-Learning and Virtual Reality [1]

Due to the nature of spatial visualization, many students need to see and interact with 3D scenes to get tangible feelings of the 3D model. The outcomes of this research include but is not limited to the following: a better understanding of online education, how to enhance 3D spatial visualization skills with the use of Virtual Reality technology, a reduction in the gender gap in spatial visualization abilities and making this knowledge generalizable.

\section{Literature Review}

Constructivism is a belief of learning based on the idea that knowledge is created by the individual through his/her contacts with their environment [2]. Constructivists believe in individual understanding of reality [3]. Sjoberg S [3] argues that constructivism is a learning methodology that gives learners the opportunity to gain experiences by which they can solicit their own questions and build their own models. Sjoberg [3] also argues that constructivism enables a community of learners to participate in reflection, activities, and discourse; inspires learners to ownership of ideas and purse independence, shared social relationships, and enablement as the goal. Learning becomes a self-regulatory activity: students figure out things for themselves instead of responding to stimuli.

Constructivists argued that everyone has their own special learning style. Sometimes, the learning styles have as much to do with how the brain works as environment. Autopsies have been performed on both dyslexic and normal brains. The dyslexic brain showed even development on both spheres of the mind, while the normal mind showed asymmetrical growth in only one sphere.

Equal development of both spheres permits learning-differently students to enjoy special gifts. They "see" things 3-dimensionally, giving them a unique kind of spatial awareness. This allows some of them to be, among other things, excellent architects, inventors, directors of film and theatre, interior decorators, and teachers for other learning-differently students (students who learn differently) [4]. 


\section{Learning Styles}

Mobile learning [5] has been compared to constructivist learning involving creativity and spontaneity [6,7]. Corrent Agostinho [8] argues four general principles of a constructivistlearning situation: (1) learning is a development of construction; learning happens through social consultations of meaning; learners are occupied with authentic contexts; philosophical thinking is a final goal. "However, at the postgraduate level, provision of extensive background material as downloadable text-based or media-rich resources is vital if mobile learners are to start constructing their own understanding of complex issues" [9].

Ferriman [6] argues that there are seven categories of learning styles: visual, physical, aural, verbal, logical, social, and solitary. In the visual category, individuals use images, pictures, color, and diagrams to learn. The physical category individuals learn by doing. Aural, people use sound to learn, recordings, rhythms, and music. The verbal category, individuals use words to learn, reading aloud, speech, and writing. The logical category, individuals use logic and reasoning to comprehend a concept. Social, these individuals learn best in groups and enjoy working with others. The solitary category includes individuals that enjoy working \& learning alone. It is safe to say that most individuals have no one learning style but use a combination of styles to learn. Architect use visual, physical, logical, and solitary styles to learn.

\section{Attributes Relevant to M-learning}

First, mobile learning will not be effective unless you have highquality internet service. M-learning opportunities are created when educational technologies and resources are coupled with mobile devices. Despite socio-political isolation, cultural or geographical distance, mobile learning allows contact and communication with other professionals. Lessons from the past have taught us that effective pedagogy leads to effective learning [9]. Beckmann argues other attributes relevant to mobile learning include: rather than the technology, it is the student that is mobile; learning is intertwined with other actions as part of life; learning can produce as well as gratify goals; the management and control of learning can be dispersed; context is built by students through interaction; formal education can both conflict and complement mobile learning; mobile learning increases ethical issues of ownership and privacy.

Mobile learners construct their own conceptual understanding of the social and physical world and interact accordingly. Gary Long \& Carol Marchetti [10] argue, that students that take online courses with high levels of interaction make better grades, report more learning than students in similar face-to-face classes.

\section{M-Learning}

It has been argued by many that the best predictors of student satisfaction with online courses are learner-instructor interaction, internet (and software) self-efficacy, and learnercontent interaction. It was also argued that gender, year in school, and learner-learner interaction were not factoring in student satisfaction with online courses. Barriers to M-Learning include internet down, cheating, miscommunication, and lack of student motivation. Architectural students claim to learn best with visual instruction, followed by 'real world' context [1].
A survey given to online architectural graduate students in 2013, revealed that they learn best with visual information, followed by real world contexts and third with verbal information. Graduate students appeared to be very satisfied with their learnerinstructor interaction; not as enthusiastic or satisfied with learnerlearner interaction; showed mixed satisfaction for authentic learning; expressed some satisfaction for active learning and personal relevance. The majority of students expressed satisfaction with student autonomy and their online class. The scales that brought the students the most satisfaction are Learner-Instructor Interaction, Active Learning, Student Autonomy, and Satisfaction with M-Learning [1].

Graduate students listed "anytime, anywhere learning" as one of the major benefits to M-Learning. Some of the barriers to M-Learning mentioned were software, missing personal connections, communication, and D2L. Students commented that video and recorded lectures along with online D2L classes would help improve M-Learning [1]. Felix Kamuche [11] argues "This study provides clear evidence that faculty can use learning styles data to help them design creative matches with students learning preferences. ...Clearly, the author can say students learned better when instruction was geared toward their learning style". Everyone has their own learning style(s); M-Learning for architectural students should include more visual and real-world contexts, followed by verbal information for best results. Interaction between teacher and student, real world problems, and making their own decisions about learning, gives architectural students the most satisfaction with M-Learning.

Scribner \& Anderson [12] argue the success of integrating teaching methods that enhances different learning styles to improve scholarship.

The literature review and the results of this research study support the following recommendations for teaching graphical representation. Educators in technical education programs should Incorporate instructional methods that address modality learning styles when teaching spatial visualization.

1. Use modality learning styles to help students with a single dominant learning style strengthen weaker learning styles

2. Incorporate tools such as sketching, three-dimensional handheld models, three-dimensional solid model software, and orthographic and isometric projections to aid in developing spatial visualization [12].

\section{Spatial Visualization}

Spatial ability is characterized as one's innate capability to visualize and rotate objects, mentally, before formal training, i.e., one is born with the gift [13]. But spatial visualization skills can be acquired or learned through training. "It is well documented that spatial visualization skills are teachable [14-16].

Sheryl Sorby [17] was one of the first researchers to connect the gender gap with spatial visualizations skills. "Unfortunately, studies show that 3-D spatial visualization skills of women often lag behind those of their male counterparts" [18-21]. Smith [22] and Maier (1994) found visualization skills to be a major predictor of success 
in technical professions. In her paper, Sort by explains the Piagetian theory of the three stages of spatial visualization development, the Purdue Spatial Visualization Test, and the development of a new curriculum to improve spatial visualization skills. The course consisted of four hours of lab and lecture per week for ten weeks, computer lab manual, textbook, and instructional aids. The Preand Posttest responses were studied according to gender; spatial visualization skills improved overall but the gender gap continued to exist $[18,23,24]$.

It is argued that computer \& video games, physical sports, construction toys, and courses such as drafting, math, and shop have a positive relationship with $3 \mathrm{D}$ spatial visualization skills $[17,18,25,26]$.

Sorby argues that spatial visualization skills training has a positive impact on grades earned, student retention and graduation rates for students of all ages, especially underrepresented minorities and women [27]. Yet in another study "it was determined that the spatial skills of some minority groups, in particular African Americans, Asian Americans, and Native American males, appear to be significantly lower than those of White students" [28]. The spatial skills of international students were also found to be behind the majority of American students.

Toptas, et al. [29] in their study of 8th graders using Google Sketch Up (GSU) software, argues that there was a significant increase in spatial visualization skills, differential aptitudes, and mental rotation skills after the posttests. The use of Google Sketch Up helped to improve all students' spatial visualization skills; but female students, compared to male students, performed better on the posttests [29].

If the debate is to be moved forward, a better understanding of other types of training programs that increase spatial visualization such as three-dimensional virtual reality programs need to be developed. We may want to revise our treatment program. Students may require more time outside of the classroom to work with GSU. If students are provided with a computer for use, we can log the amount of time they use the software and for what purpose [29].

Feng, et al. [30] argue that existing learning materials and courses are not well suited to aid students in developing their spatial visualization skills and that a new approach is needed. "The main contention of this study is that a thorough understanding of students learning styles and abilities combined with the exploitation of advances in Virtual Reality technology, especially online Virtual Reality applications, has the potential to offer an effective instruction tool for improving CAD student's spatial visualization skills" [30]. A learning environment of virtual models in Web3D will allow students to gain a better understanding of 3D objects and increase their spatial visualization skills [30].

Ji Young Cho [31] questions whether the existing spatial visualization test are 'domain-specific' and if they should be. If the tests are domain-specific, one domain does not fit everyone. Cho also argues improvement of spatial visualization scores by way of virtual reality technology.
This raises a question about whether existing tools measure domain-specific spatial ability as well and hether the development of tool to measure domain-specific spatial skills are needed. In research of and training for spatial ability, one of the recent changes regards the use of virtual environment technologies. Many recent publications [32] have reported the improvement of spatial tests through the use of virtual reality Cho [31].

Dayana Farzeeha Ali, et al. [33] argues students that are taught with virtual environment courseware have improved skills of mentally rotating 3D objects and visualizing cross sections of objects. "New and innovative approaches to using technology, including the use of various hardware and software, has shifted the paradigm and introduced nontraditional methods teaching and learning" [34]. Spatial visualization skills of students are positively enhanced by virtual environment courseware [35,36]. "The findings from this study support the conclusion that the virtual learning environments become one of the key factors in the delivery of education in the higher learning institutions" Ali, et al. [33].

Distinct advantages of virtual learning environments include: the mobile learning aspect gives students anytime, anyplace access; the unique character of virtual reality is a motiving influence to students to increase their spatial visualization skills; and the technology of Web3D which integrates Flash, XML, HTML, 2D drawings and 3d models Feng, et al. [30].

In addition, it has been established that existing tutorials and learning materials are not well suited to assist students in developing their spatial ability. It is increasingly acknowledged that there is a need for a new approach, which fosters CAD students' spatial visualization skills... It is the contention of this study that a thorough understanding of students' characteristics, learning styles and abilities combined with the exploitation of advances in Virtual Reality technology, especially online Virtual Reality applications, has the potential to offer an effective instruction tool for improving CAD students' spatial visualization skills Feng, et al. [30].

Jianping Yue [37] used first year community college and high school students to perform a classical experiment, using control and experimental groups to test spatial visualization performance with conventional isometric drawings and realistic 3D views. He found that all groups that studied with realistic 3D views performed better on the spatial visualization tests than the control groups $[38,39]$. The high school group studying realistic 3D images showed the greatest improvement, with a 15\% increase on their posttests. "The study results provide evidence that 3D solid model enhances students' performance on visualization tests, thus making it a better tool to be used in spatial visualization tests to help students visualize virtual objects and to allow educators to obtain accurate assessments of students' visualization abilities" [37].

\section{Promoting Generalizability and Transferability of the New Genre}

The most practical issues addressing this new genre is how to improve one's visualization skills and how do you reduce the adjoining gender gap. We believe the answer to both questions are 'Virtual Reality'. Literature reviews has shown that the use of 
virtual reality has significantly improved one's spatial visualization skills while all but eliminating the gender gap. Current research includes: middle \& high school students learning science by means of mixed-reality technologies, augmented reality technologies, Internet System for Networked Sensor Experimentation (iSENSE) technologies, simulation and embodied learning, gaming toward positive social behaviors and health, collaborative problem solving through digital sketching \& touch, Per Sketch Tivity - empowering engineers through perspective sketching (something architects have been doing for years - digitally sketching), workflow visualization systems for design-based research, using gaming to improve visualization skills, removing gender differences in 3-D spatial skills, and multi-media software for the development of 3-D spatial visualization ability.

Our new learning platform incorporates the majority of the above research but is developed along a new paradigm using both 'learning styles' and architecture. The existing engineering models has had limited success for the last twenty-five or more years; our new learning platform, incorporates among other features '3D \& Virtual Reality software', is ideal for addressing today's issues. Some of the weaknesses of our solution are the dependence upon the internet, computers, and headgear.

The type of lessons we are expecting to extract from this innovation include; how do students use virtual reality activities; what kind of practices and new opportunities will virtual reality afford students and teachers; and how do these new opportunities relate with learning? We know that virtual reality is more effective than similar activities without simulations and sensors, but does it promote deep and coherent learning? And what kind of curriculum and instructor support best enhances scholarship based virtual reality learning?

\section{Methodology}

The research methodology is a combination of quantitative and qualitative methods. The qualitative methods we have already seem in the literature review. The quantitative methods come by way of Virtual Reality course projects and open-ended survey questions given to the 2017 online Graduate Architectural Thesis Studio and 2017 Senior Urban Design face-to-face studio. Both classes received the same open-ended survey with the exception that the seniors were asked for extra credit to explain by way of essay, the process they used for their virtual reality presentation.

\section{Analysis of Data}

The graduate thesis studio had eleven (11) students and the senior urban design studio had twelve (12) students. Each graduate student was asked to draw a virtual reality 3D walkthrough in and around their thesis building project. The senior urban design studio was organized into four groups of three students each and asked to draw a virtual reality 3D walkthrough around their design project. The seniors were also given extra credit if they could transfer the 3D walkthrough into their smart phones to be used in virtual reality headsets supplied by the school. Both architectural studios were asked the same four (4) open-end questions:

1. Have you ever drawn 3D's walkthroughs before?

\section{Did you find the 3D walkthroughs difficult?}

3. Was drawing the 3D's walkthrough a good educational experience?

4. Tell me in your own words what you thought of the 3D walkthrough experience, your opinion of the exercise, and how it could be improved.

The graduate thesis students were about even on Question \#1, having drawn a 3D walkthrough in the past, with five (5) 'Yes' and six (6) 'No' answers. Question \#2, finding the 3D's difficult, had the same split, with five (5) 'Yes' and six (6) 'No' answers; most thought that the experience was very time consuming. For Question \#3, all eleven (11) students thought that the 3D's walkthroughs were a good educational experience. Students comments to Question \#3 include the following:

Creating the 3D panorama tours that I have decided to purse are great educational experience in my opinion. It has helped me to really explore the space and make changes based on how the interior perspectives hanges when you turn around in the space [40].

I find the 3D walk-through very educational because it is the visual aspect of all of these individual design elements come together for a vision of a project that is un-built. It gives the designer and users an idea how the space will feel and how users can move through the space. Where spaces may be too tight, or feel too large, where views are blocked (privacy) and framed (focal point). Walkthroughs visually help make sure the design is on track [41].

Some of the graduate comments to Question \#4, what they thought of the 3D experience are as follows:

It's very time consuming but in the end, very informative in showing things you may not have visualized in the design [42].

I think that 3D walkthroughs are another tool in the architect's toolbox and can come in handy for certain jobs to better show a client what something might feel and look like. ...All that being said I think the 3D experience is the way the industry is trending and will become a necessary skill to have [43].

My experience with the walk-through has been good overall, time consuming and hard on the computer, but it has definitely helped aid in the overall design of my project and gives the audience a better understanding. I think you are on the right path as VR is becoming more integrated into the design and architecture field. One tip would be to explore the different software/options for the student earlier as it seems many are not familiar with the method and delivery [44].

It is of interest to note that of the eleven graduate students, the two female students decided to develop 'Panorama 360 pictures' instead of a 3D walk-through video. The 'Panorama' is a device where you link six digital pictures together to give you a 360 view of one space; not nearly equal to the visualization experience of the 3D walk-through of the entire building. This appears to be an example of the gap in spatial visualization skills between men and women. 
The seniors were more at ease with the 3D walkthroughs than the graduate studio; it is believed that the youth of the studio and group efforts made the difference. For Question \#1, only one (1) student out of twelve (12) had previously drawn a 3D walk-through. But nine of the twelve (12) students expressed no difficulty doing so. And for Question \#3, all twelve students thought that the 3D walkthroughs were a good educational experience. In answering Question \#3, one of the groups stated the following:

As a group, we do think creating walk-throughs were a good learning experience. The walk-through allows us as designers to better translate our design to our clients, so learning how to create these realistic walk-throughs will help us in the future as grad students and while working in an architectural firm [45].

In Question \#4, the seniors were to express in their own words the 3D walk-through experience:

We think 3D walk-throughs will become increasingly common in the future. As technology and our skills advance, they will become easier to make, yet more complex in character [46].

As a group, we agree that it was beneficial to our design and a good exercise in 3D rendering software. Improvements that could be made is incorporating the 3D walkthrough into a semester long project, so there will be ample time to create a quality walkthrough and develop the project on a more human scale [47].

The senior urban design studio was also given extra credit if they use essay form to describe constructing their 3D walk-throughs presentations and putting them into Virtual Reality headsets. Most of their essays were similar with the exception of whether they used Sketch-up or Revit software:

For our groups personal experience with the 3D walk-throughs, we started by creating our sites, buildings, etc. in Sketch-up, so that we had all of the spaces and faces of buildings finished. We then took that master Sketch-up file and put it into the rending software Lumion. While in Lumion we each took our perspective views, added land-scaping, people, vehicles, and updated building materials to create the most realistic environments we could. Once everything was added, our perspectives were taken, and we took a series of screen shots through the site in a way that provided the walk-through. Lumion then knotted all of these images into one smooth movie style walk-through. This file was then rendered for multiple hours to produce an HD quality experience. To get this video into the goggles, just upload the rendered movie file into iFun Video Converter to make it VR compatible. The final step is for adding music to the video and all you have to do is load your final movie into windows movie maker and load an audio track that fits your design feel [45].

From this analysis, it has become apparent that younger designers (seniors) have an easier time with the 3D software and instruction than the older ones (graduate students). And that group work makes the 3D virtual reality project easier.

\section{Conclusion}

This research has proven its hypotheses, that Virtual Reality technology does enhance 3D spatial visualization skills of students, for both online and face-to-face classes. Due to the nature of their learning styles, many students need to interact with 3D scenes to enhance their spatial visualization skills, to see and understand the 3D model. The comments of students indicate that Virtual Reality gives them a better understanding of their building project than a physical model. Students need very little instruction from their professors to learn how to use Virtual Reality technology; they are for the most part self-taught. It also appears that Virtual reality does promote deep and coherent learning.

It is hypothesized that training students in 3D Virtual Reality technology, especially females, will help reduce the gender gap in spatial visualization abilities. This new Virtual Reality learning platform is developed along a new paradigm using both 'learning styles' and architecture design classes to teach. Engineering disciplines will be able to easily copy and adapt this new paradigm.

The next step for this research is to conduct semester long Virtual Reality training projects, to see if the spatial visualization gap between genders can be reduced. The Virtual Reality training should begin with a face-to-face junior architectural design studio.

\section{Acknowledgement}

None.

\section{Conflict of Interest}

No conflict of interest.

\section{References}

1. Brazley M (2014) How Students Learn with Mobile Technology. USChina Education Review A 4(6).

2. Rovai AP (2004) A constructivist approach to online college learning. Internet and Higher Education 7(2): 79-93.

3. Sjoberg S (2007) Constructivism and learning. In E Baker, B Mc Gaw, P Peterson (Eds), International Encyclopedia of Education ( $\left.{ }^{\text {rd }} \mathrm{edn}\right)$.

4. Alsenoy Susan (2011) Students Who Learn Differently Overseas: Learning Differently.

5. Laurillard D (2007) Pedagogical forms for mobile learning. In N Pachler (Eds), Mobile learning: Towards a research agenda. London: WLE Centre, Institute of Education.

6. Ferriman J (May 2013) 7 Major Learning Styles - Which One are You?

7. Herrington A, Herrington J (2007) Authentic mobile learning in higher education. Paper presented at the Australian Association for Research in Education (AARE) 2007 Conference, Fremantle.

8. Agostinho S (2005) Naturalistic inquiry in e-learning research International Journal of Qualitative Methods 4(1).

9. Beckmann EA, Kilby P (2008) On-line, off-campus and in the flow: Learning from peers in development studies. Australasian Journal of Peer Learning 1(1): 61-69.

10. Long G, Marchetti C, Richard Fasse (2011) The importance of Interaction for Academic Success in Online Courses with Hearing, Deaf, and Hardof-Hearing Students. The International Review of Research in open and Distance Learning 12(6).

11. Kamuche FU (2005) Do Learning \& teaching Styles Affect Students' Performance? An Empirical Study. Journal of Business \& Economics Research 3(9).

12. Scribner S, MA Anderson (2005) Novice Drafters' Spatial Visualization Development: Influence of Instructional methods and Individual Learning Styles. Journal of Industrial Teacher Education 42(2).

13. Sorby SA (1999a) Developing 3-D Spatial Visualization Skills. Engineering Design Graphics Journal 63(2). 
14. Battista MT, HW Grayson, G Talsma (1982) The Importance of Spatia Visualization and Cognitive Development for Geometry Learning in Preservice Elementary School Teachers. Journal for Research in Mathematics Education 13: 332-340.

15. Brinkman EH (1966) Programmed Instruction as a Technique for Improving Spatial Visualization. Journal of Applied Psychology 50: 172 184.

16. Lappan G (1983) Middle Grades Mathematics Project. Presentation at the National Council of Teachers Mathematics National Meeting. Detroit.

17. Gimmestad B, Sorby SA (1996) Introduction to 3-D Spatial Visualization. Prentice Hall

18. Gorska R, Sorby SA, Leopold C (1998) Gender Differences in Visualization Skills -An International Perspective. Engineering Design Graphics Journal 62(3).

19. Maier PH (1994) Raeumliches Vorstellungsvermoegen, Frankfurt aM Berlin, Bern, New York, Paris, Wien: Lang.

20. Sorby SA (1966a) Improving the 3-D Spatial Visualization Skills of Women Engineering Students. ASEE Annual Conference Proceedings. Washington, DC.

21. Sorby SA (1999b) Spatial Abilities and their Relationship to Computer Aided Design Instruction. American Society for Engineering Education (ASEE), Annual Conference, Session 1438.

22. Smith M (1964) Spatial ability-Its educational and social significance. London.

23. Sorby SA, B J Baartmans (2000) The Development and Assessment of a Course for Enhancing the 3-D Spatial Visualization Skills of First Year Engineering Students. Journal of Engineering education 89(3): 301-307.

24. Sorby SA (2009) Educational Research in Developing 3-D Spatial Skills for Engineering Students. International Journal of Science Education 31(3): 459-480.

25. Medina AC, HBP Gerson, SA Sorby (1998) Identifying Gender Differences in the 3-D Visualization Skills of Engineering Students in Brazil and in the United States. U.S. Department of Education Office of Educational research and Improvement (OERI). National Library of Education (NLE) Educational resources Information Center (ERIC)

26. Nehring GA (2017) Grad Arch Des/Thesis II - ARC 554-943.

27. Study NE (2011) Long-Term Impact of Improving Visualization Abilitities of Minority Engineering and Technology Students. American Society for Engineering Education.

28. Sorby SA (2012) Spatial Skills Training to Improve Student Success in Engineering. 2012 Specialist Meeting - Spatial Thinking Across the College Curriculum.
29. Toptas V, S Celik, ET Karaca (2012) Improving $8^{\text {th }}$ Grades Spatial Thinking Abilities Through A 3D Modeling Program. Turkish Online Journal of Educational Technology 11(2).

30. Feng X, C Morgan, V Ahmed (2004) Developing visualization skills - a Virtual Spatial Training (VST) system. Conference on Construction Application of Virtual Reality, ADETTI/ISCTE, Lisbon.

31. Cho Ji Young (2012) Three Areas of Research on Spatial Ability in the Architectural Design Domain. Architectural Engineering Technology.

32. Rafi A (2008) Practising mental rotation using interactive Desktop Mental Rotation Trainer (iDeMRT). British Journal of Education technology 40(5).

33. Ali DF, Nasir ANM, Buntat Y, Minghat AD, Hussin MNK, et al. (2013) Virtual Environment Courseware in Engineering Drawing to Enhance Students' Visualization Skills. Engineering Education Symposium.

34. Bertoline GR, Wiebe EN, Miller CL, Nasman LO (2005) Fundamentals of Graphics Communication ( $4^{\text {th }}$ edn). New York: McGraw-Hill Higher Education.

35. James KH, GK Humphrey, T Vilis, B Corrie, R Baddour, et al. (2002) Active and passive learning of three-dimensional object structure within an immersive virtual reality environment. Behavior Research Methods, Instruments, \& Computers 32(3): 383-390

36. Veide Z, V Strozeva (2013) Effect of Augmented Reality Technology on Spatial Skills of Students. The $12^{\text {th }}$ International Conference on Engineering Graphics.

37. Yue J (2008) Spatial Visualization by Realistic 3D Views. Engineering Design Graphics Journal 72(1): 28-38.

38. Katsioloudis PJ, V Jovanovic (2014a) Spatial Visualization Ability and Impact of Drafting Models: A Quasi Experimental Study. Engineering Design Graphics Journal (EDGJ) 78(2).

39. Katsioloudis P, V Jovanovic, M Jones (2014b) A Comparative Analysis of Spatial Visualization Ability and Drafting Models for Industrial and Technology Education Students. Journal of technology Education 26(1).

40. Clevenger A (2017) Grad Arch Des/Thesis II - ARC 554-943.

41. Henderson C (2017) Grad Arch Des/Thesis II - ARC 554-943.

42. Nehring GA (2017). Grad Arch Des/Thesis II - ARC 554-943.

43. Hunt R (2017) Grad Arch Des/Thesis II - ARC 554-943.

44. Williams M (2017) Grad Arch Des/Thesis II - ARC 554-943.

45. McKnight R (2017) Urban Design Studio.

46. Wells (2017) Urban Design Studio.

47. Beatty A (2017) Urban Design \& Community - ARC 451-001 